\title{
Reconstruction of right ventricular outflow tract stenosis and right ventricular failure after Ross procedure - comprehensive assessment of adult congenital heart disease with four-dimensional imaging: a case report
}

Masao Takigami ${ }^{1}$, Keiichi Itatani ${ }^{2}$, Naohiko Nakanishi ${ }^{1}$, Hiroko Morichi ${ }^{2}$, Teruyasu Nishino ${ }^{3}$, Shohei Miyazaki ${ }^{3}$, Kosuke Nakaji ${ }^{4}$, Michiyo Yamano ${ }^{1}$, Yo Kajiyama ${ }^{5}$, Yoshinobu Maeda ${ }^{6}$, Satoaki Matoba ${ }^{1}$, Hitoshi Yaku and Masaaki Yamagishi ${ }^{6}$

\section{Abstract}

Background: Re-intervention after Ross procedure into the right ventricular outflow tract might be needed in patients in the long term. However, right ventricular outflow tract re-intervention indications are still unclear. Comprehensive assessment of total hemodynamics is needed.

* Correspondence: keiichiitatani@gmail.com

${ }^{2}$ Department of Cardiovascular Surgery, Kyoto Prefectural University of

Medicine, Kyoto, Japan

Full list of author information is available at the end of the article

(c) The Author(s). 2020 Open Access This article is licensed under a Creative Commons Attribution 4.0 International License, which permits use, sharing, adaptation, distribution and reproduction in any medium or format, as long as you give appropriate credit to the original author(s) and the source, provide a link to the Creative Commons licence, and indicate if changes were made. The images or other third party material in this article are included in the article's Creative Commons licence, unless indicated otherwise in a credit line to the material. If material is not included in the article's Creative Commons licence and your intended use is not permitted by statutory regulation or exceeds the permitted use, you will need to obtain permission directly from the copyright holder. To view a copy of this licence, visit http://creativecommons.org/licenses/by/4.0/. The Creative Commons Public Domain Dedication waiver (http://creativecommons.org/publicdomain/zero/1.0/) applies to the data made available in this article, unless otherwise stated in a credit line to the data. 
(Continued from previous page)

Case summary: A 42-year-old Japanese woman was referred to our hospital for moderately severe pulmonary regurgitation and severe tricuspid regurgitation after a Ross-Konno procedure. Thirteen years after surgery, she developed atrial fibrillation and atrial flutter and complained of dyspnea. Electrophysiological studies showed reentry circuit around the low voltage area of the lateral wall on the right atrium. Four-dimensional flow magnetic resonance imaging revealed moderate pulmonary regurgitation, severe tricuspid regurgitation, and a dilated right ventricle. Flow energy loss in right ventricle calculated from four-dimensional flow magnetic resonance imaging was five times higher than in normal controls, suggesting an overload of the right-sided heart system. Her left ventricular ejection fraction was almost preserved. Moreover, the total left interventricular pressure difference, which shows diastolic function, revealed that her sucking force in left ventricle was preserved. After the comprehensive assessments, we performed right ventricular outflow tract reconstruction, tricuspid valve annuloplasty, and rightside Maze procedure. A permanent pacemaker with a single atrial lead was implanted 14 days postoperatively. She was discharged 27 days postoperatively. Echocardiography performed 3 months later showed that the size of the dilated right ventricle had significantly reduced.

Discussion: A four-dimensional imaging tool can be useful in the decision of re-operation in patients with complex adult congenital heart disease. The optimal timing of surgery should be considered comprehensively.

Keywords: Ross procedure, 4D flow MRI, Flow energy loss, Pulmonary regurgitation, Right ventricular deterioration, Case report

\section{Introduction}

Although the long-term results of the Ross procedure have been improving with acceptable low mortality, it is common that a re-intervention of the right ventricular outflow tract (RVOT) might be needed in the long term, in addition to treating aortic valve or aortic root $[1,2]$. However, an indicator of RVOT re-intervention is still unclear due to the lack of comprehensive assessment tools of right-sided heart hemodynamics. Assessing the load of the right-sided heart system combined with the left ventricular (LV) outflow tract might be a useful way to decide on the timing of the re-intervention.

We present the case of a 42-year-old woman who underwent the Ross procedure 13 years ago. Comprehensive assessments that included four-dimensional flow magnetic resonance imaging (MRI), electrophysiology studies, and sucking force of the left ventricle measured via echocardiography, that is, interventricular pressure difference (IVPD), were quite useful in the assessment of total hemodynamics and thus a successful surgical treatment was performed.

\section{Case presentation}

A 42-year-old Japanese woman was referred to our hospital for moderate to severe pulmonary regurgitation (PR) and severe tricuspid regurgitation (TR). Her medical history showed a coarctation repair at 9-years old and an aortic valve replacement (AVR) at 25-years old for congenital aortic stenosis. However, perioperative myocardial infarction in the anteroseptal region occurred just after the AVR, and she underwent RossKonno procedure using $24 \mathrm{~mm}$ Gore-Tex ${ }^{\circledR}$ grafting with a bulging sinus of the tricuspid valve in the RVOT position. Seventeen years after the surgery, atrial fibrillation (AF) and atrial flutter (AFL) occurred and she complained of dyspnea.

An electrocardiogram showed signs of sinus bradycardia (heart rate 48/minute), first-degree of atrioventricular block, and a fragmented wide QRS (167 ms) with complete right bundle branch block (Fig. 1a). The echocardiogram demonstrated moderately severe PR and TR and that the LV contraction was preserved regardless of hypokinesis in the septal region due to myocardial infarction (ejection fraction was 48\%) (Fig. 1b and c). A three-dimensional echocardiogram measured that right ventricular end-diastolic volume index/right ventricular end-systolic volume index (RVEDVI)/(RVESVI) was $147 / 82 \mathrm{~mL} / \mathrm{m}^{2}$. Electrophysiological studies showed the re-entry circuit to be around the low voltage area on the lateral wall of the right atrium; this re-entry leads to AFL (Fig. 2). In order to assess her right-sided heart hemodynamics in detail, we performed four-dimensional flow MRI. Four-dimensional MRI could separately evaluate $\mathrm{PR}$ and TR; regurgitant volumes (RVol) and regurgitant fractions (RF) of PR were calculated as $18.38 \mathrm{ml}$ and $17.7 \%$, which is estimated to be a moderate degree, and the values of TR were calculated as being $47.16 \mathrm{ml}$ and $35.5 \%$, which were estimated to be of a severe degree (Fig. 3). RVEDVI and RVESVI was $158.63 / 58.56 \mathrm{~mL} / \mathrm{m}^{2}$, and the cardiac index $(\mathrm{CI})$ was $3.18 \mathrm{~L} /$ minute per $\mathrm{m}^{2}$. Her right ventricle (RV) was slightly dilated but had not reached the point of indication for re-operation. The cardiac output was preserved. However, flow energy loss (FEL) in RV calculated from four-dimensional flow MRI was $5.19 \mathrm{~mW}$, which is estimated to be five times higher than normal controls, suggesting an overload of the 


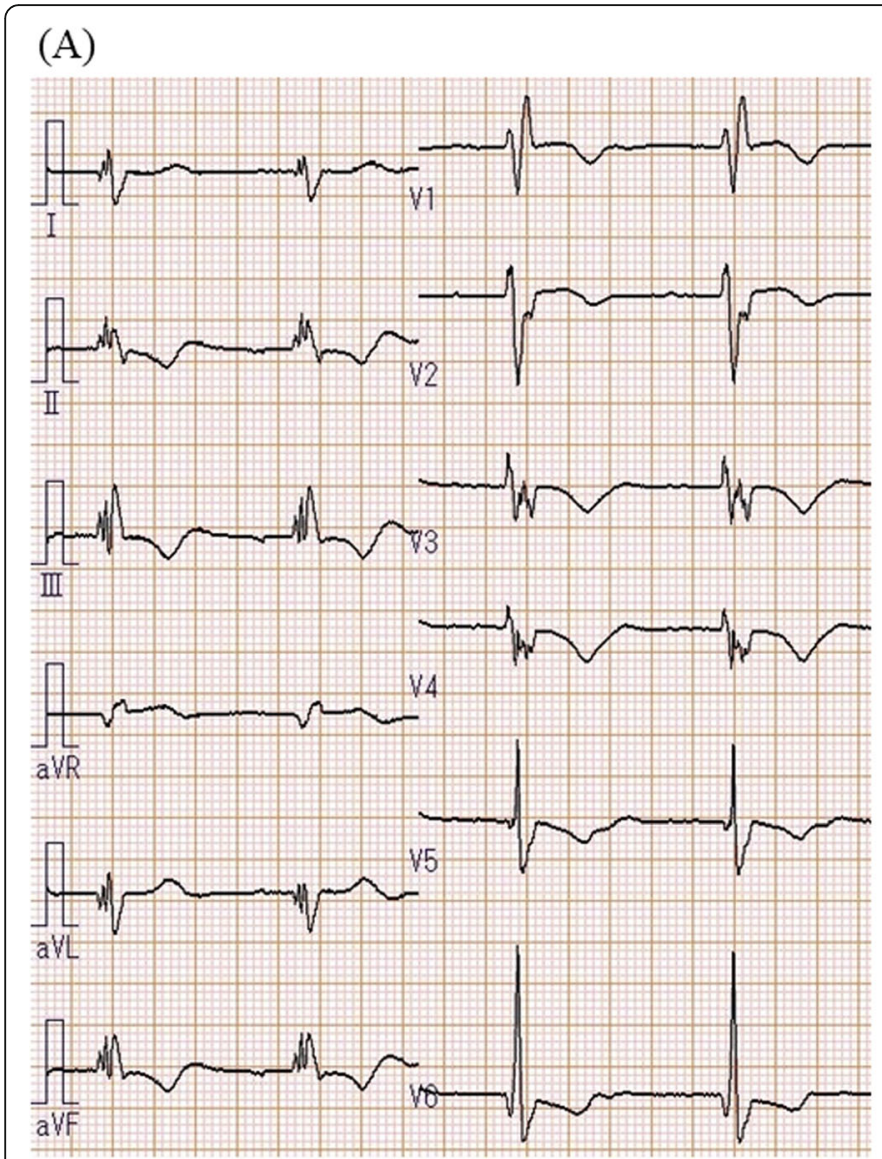

(B)

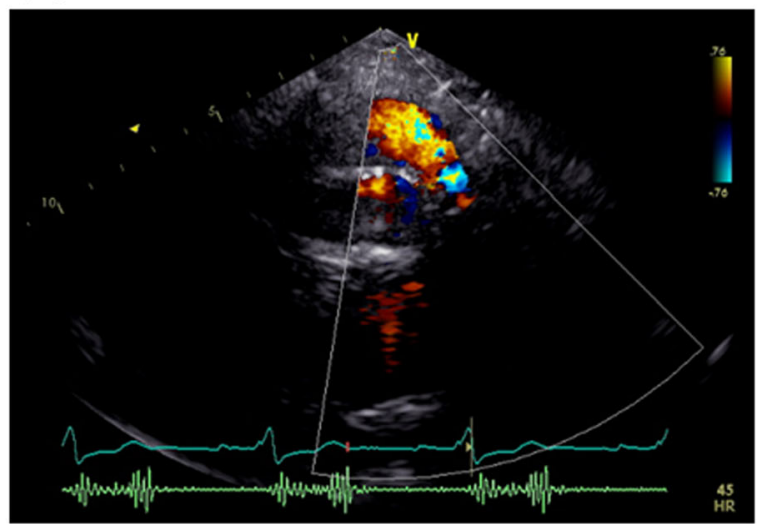

(C)

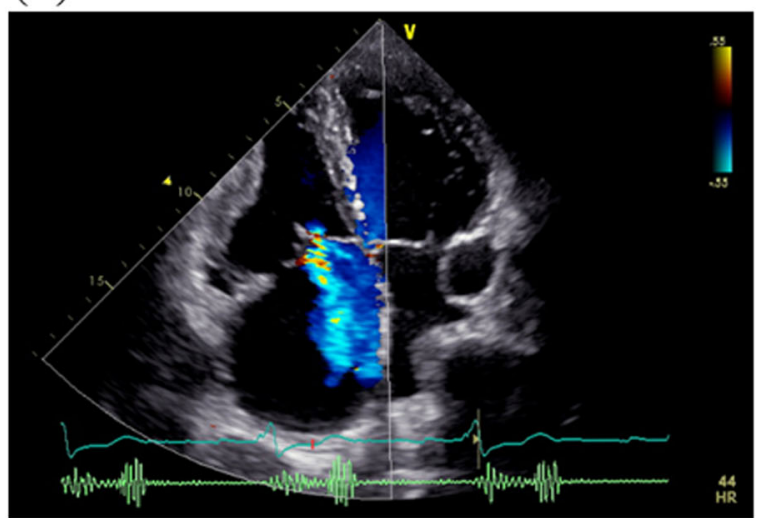

Fig. 1 Electrocardiogram and echocardiogram. a Electrocardiogram showed fragmented wide QRS (167 ms) with complete right bundle branch block. b, c Echocardiogram revealed dilated right ventricular chamber and revealed moderately severe pulmonary regurgitation and

tricuspid regurgitation

right-sided heart system (Fig. 4). Although she had a past history of myocardial infarction, the LV ejection fraction (LVEF) was almost preserved at 55.5\%, and a thallium-201 single-photon emission computed tomography scan did not reveal any myocardial ischemia. We had to assess her LV function in detail, not only the contractions but also the diastolic function, in order to assess whether her left ventricle could receive the necessary volume from the right side of her heart after re-intervention. Total left IVPD, which was calculated based on mitral inflow measurements from color Mmode Doppler echocardiography, was $2.36 \mathrm{mmHg}$. Midto-apical IVPD, which was measured as two-thirds of the LV length, was $1.09 \mathrm{mmHg}$ (Fig. 5). These findings show that her sucking force in left ventricle was preserved.

We decided to perform RVOT reconstruction (RVOTR), tricuspid valve annuloplasty, and right-side Maze procedure. The previous expanded polytetrafluoroethylene (ePTFE) conduit was degenerated with calcification. A new $24 \mathrm{~mm}$ ePTFE tricuspid valve conduit was placed in the RVOT position. Concomitantly, right-side Maze procedure was performed. The right atrium was incised via the lateral side of the atrium and ablation was carried out on the posterior and anterior walls of the atrium from the incision line to the tricuspid isthmus and to the inferior vena cava. Subsequently, a tricuspid annuloplasty was performed with Contour $3 \mathrm{D}^{\mathrm{m}}$.

After the procedure, atrial pacing from epicardial temporary lead was needed due to sinus dysfunction and a permanent pacemaker with single atrial lead was implanted 14 days later. She was discharged 27 days postoperatively. Although we could not measure her FEL after the operation by MRI due to pacemaker implantation, echocardiography was performed 3 months later, which showed that the size of RVEDVI/RVESVI had significantly reduced to $113.5 / 72.7 \mathrm{~mL} / \mathrm{m}^{2}$.

\section{Discussion}

The Ross procedure is one of the standard surgical procedures for congenital aortic stenosis. Compared with aortic mechanical valve replacement, the Ross procedure has various advantages, including no need for 


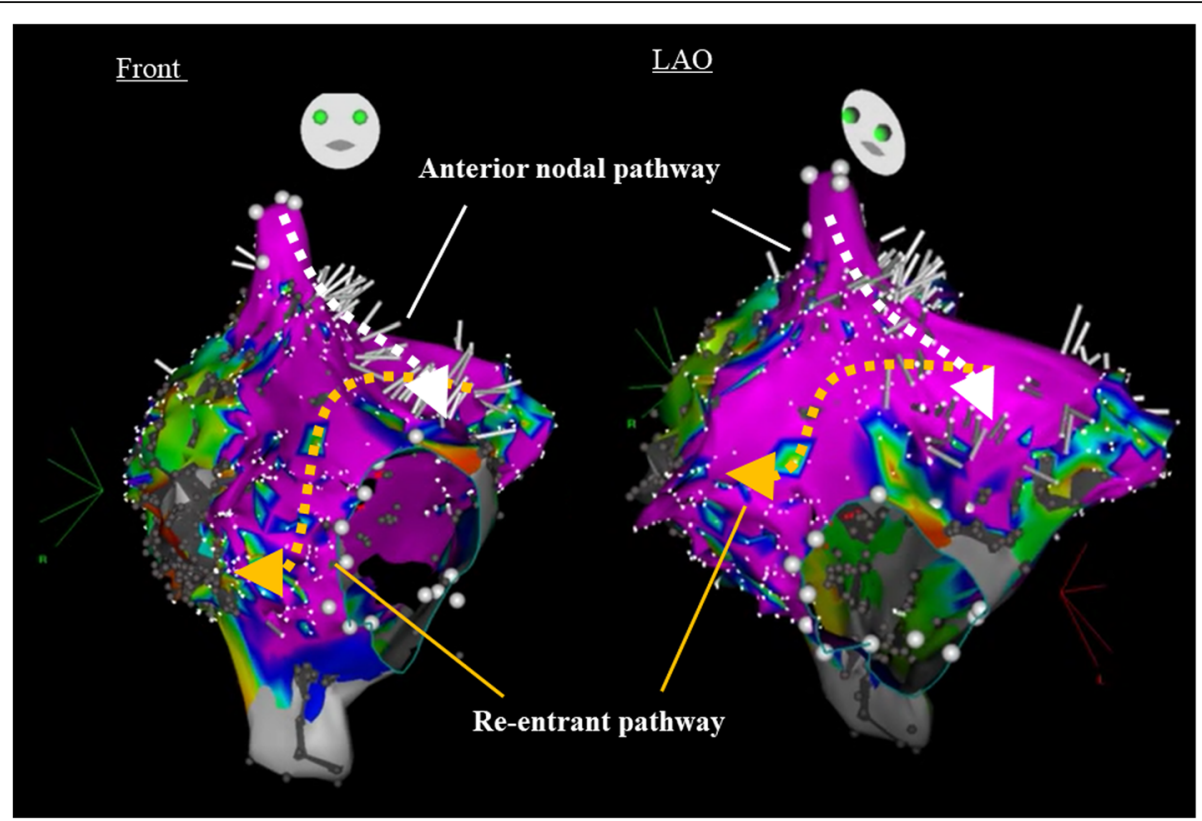

Fig. 2 Electrophysiological study. Electrophysiological study showed re-entry circuit around the low voltage area on lateral wall of the right atrium

anticoagulation medication, autograft growth, and it has excellent hemodynamics. Although the Ross procedure has an acceptable long-term survival rate of over $80 \%[1,3,4]$, late complications are still unsatisfactory. Nelson et al. showed that re-intervention in the long term is common for $87 \%$, especially after 15 years of freedom from RVOT re-operation, which is around 53\% [5]. Late complications post Ross procedure are complex due to the influence on both the left-sided and right-sided heart system and thus requires comprehensive evaluation of both the rightsided and left-sided heart system. In this case, we had several difficulties to determine the operative indications: moderate PR, moderate pulmonary stenosis
(PS), severe TR, atrial tachycardia, sinus dysfunction, and LV systolic and diastolic functions.

We comprehensively assessed cardiac workload and problems in her right-sided heart failure. FEL is known as a parameter of cardiac workload to predict ventricular deterioration in various heart diseases $[6,7]$, including heart valve disease, cardiomyopathy, and congenital heart disease. Regarding the right ventricular deterioration, Shibata et al. reported that FEL through the pulmonary valve after tetralogy of Fallot (TOF) repair was correlated with QRS duration prolongation in an electrocardiogram [8]. In our case, her FEL of the rightsided heart system calculated from four-dimensional flow MRI was very high due to the combination of

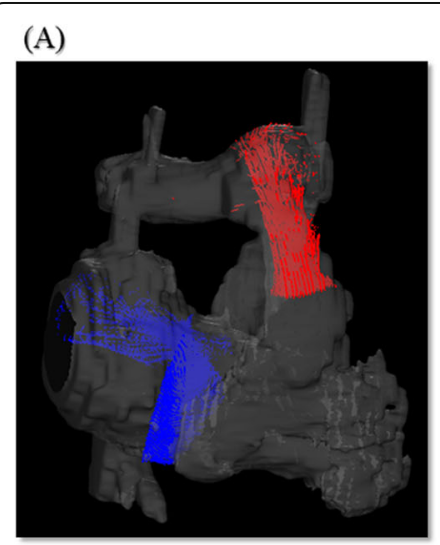

(B)

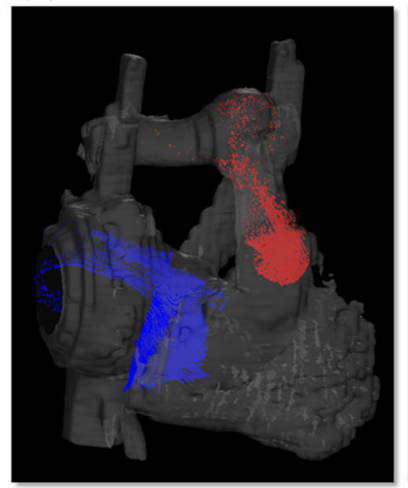

(C)

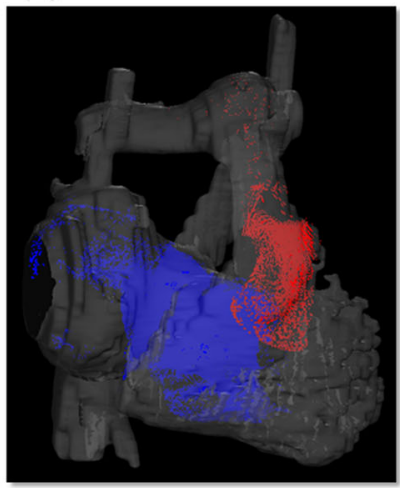

(D)

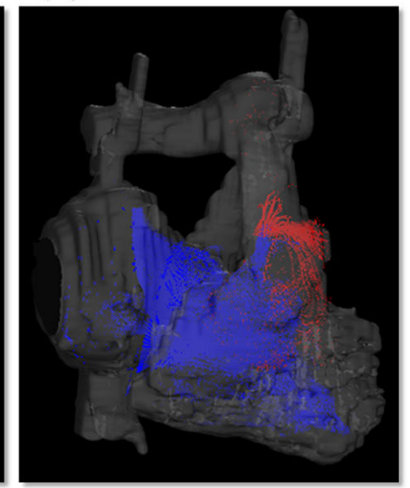

Fig. 3 Pulmonary regurgitation and tricuspid regurgitation of three-dimensional path line from four-dimensional flow magnetic resonance imaging. a Early systolic phase, b late systolic phase, c early diastolic phase, and $\mathbf{d}$ late diastolic phase 


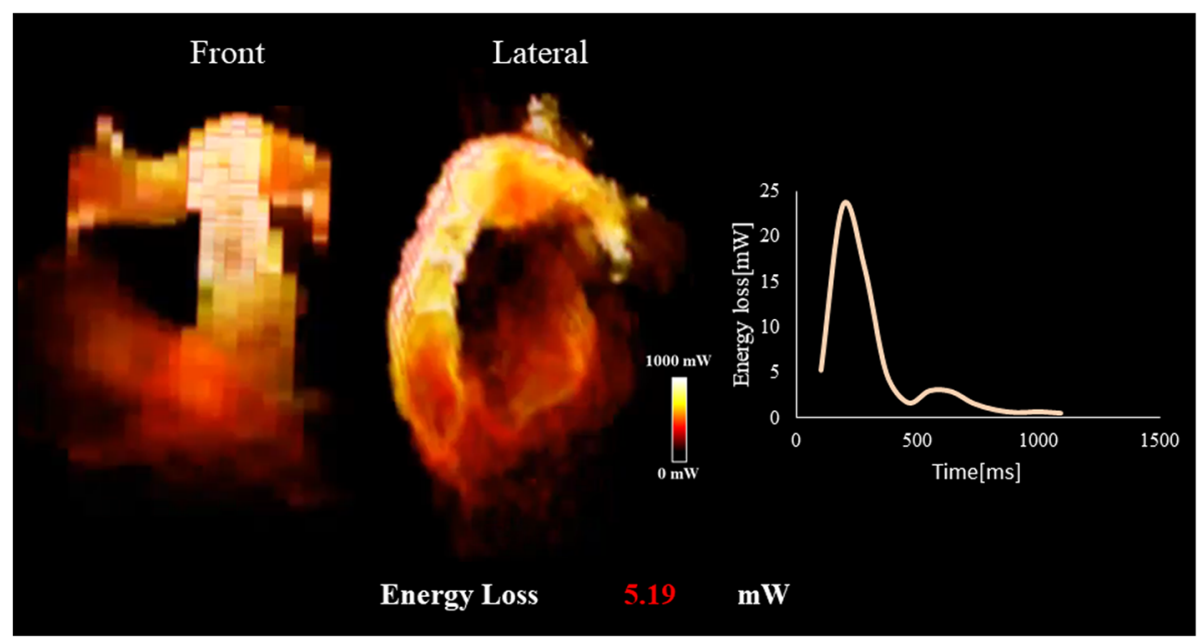

Fig. 4 Flow energy loss. Flow energy loss in right ventricle calculated from four-dimensional flow magnetic resonance imaging was $5.19 \mathrm{~mW}$, which is estimated to be five times higher than normal controls

moderate RVOT stenosis, moderate PR, and severe TR. It is reported that RV cannot obtain reverse remodeling of the normal range after pulmonary valve replacement (PVR), if re-operation is too late [9]. Integrated FEL in the right-sided heart system might be a useful tool to consider the timing of re-operation before RV dysfunction or enlargement is developed.

IVPD represents left ventricle sucking force, which has a good correlation with tau index used as the goldstandard indicator of diastolic function [10, 11]. Mid-toapical IVPD shows an indicator of active sucking force $[12,13]$. Surgical intervention of the tricuspid and pulmonary valve regurgitation increased the LV preload; therefore, the surgical indication should be carefully considered for each patient with an impaired LV function. Her total and mid-to-apical IVPD showed that her sucking forces were preserved, suggesting a good tolerance against LV volume increase after re-operation.
Arrhythmias and conduction disturbances are also common after late complications of a repaired Ross procedure. Atrial tachy-arrhythmias result in LV dysfunction, leading to systolic heart failure [14, 15]. Some reports have shown that catheter ablation for AF improved LV function and the probability of survival [16, 17]; however, atrial arrhythmic involvement in RV dysfunction has not really been explored. In this case, ablation for AFL might have been effective to improve the RV dysfunction after RVOTR. Furthermore, evaluation of this using $\mathrm{Carto}^{\circ}$ mapping enabled appropriate ablation. If atrial tachycardia had continued after the operation, ablation of atrioventricular node would have been needed to keep an appropriate heart rate. Although, in fact, she underwent a pacemaker implantation due to her sinus dysfunction, only one lead in the atrium was required after the operation. We could avoid the placement of a ventricular lead through the tricuspid valve,

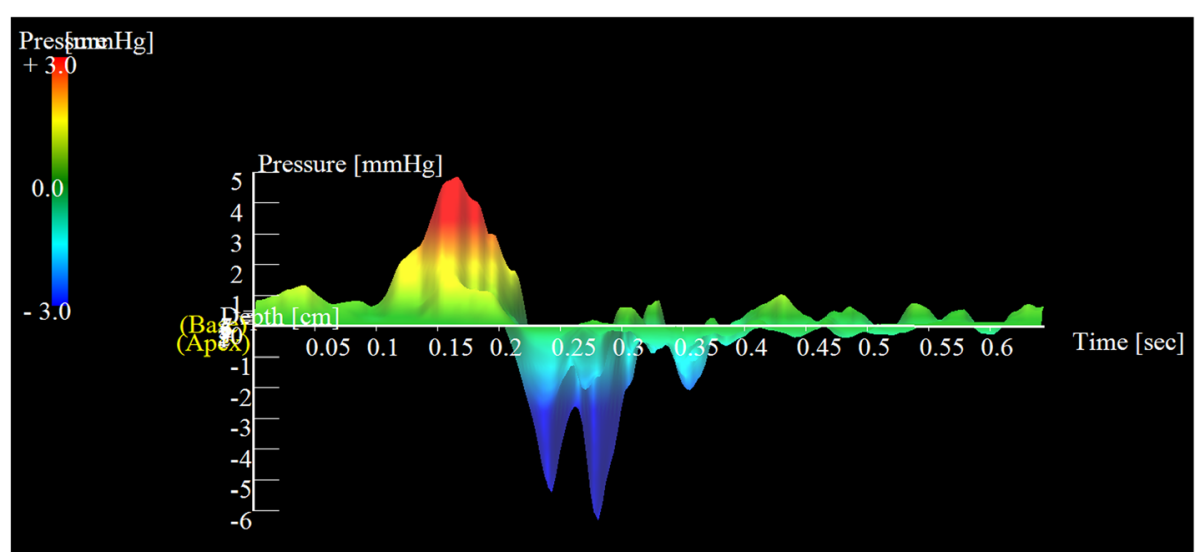

Fig. 5 Interventricular pressure difference. Total interventricular pressure difference was 2.36 mmHg and mid-to-apical interventricular pressure difference, which was measured as two-thirds of the left ventricular length, was $1.09 \mathrm{mmHg}$ 
owing to the disappearance of her arrhythmia. Because patients with adult congenital heart disease (ACHD) have often undergone several previous surgeries and their hearts are anatomically different from normal hearts, the cause of arrhythmia is often complicated. Electrical mapping before re-operation using Carto ${ }^{\circ}$ mapping is useful to treat arrhythmia in patients with $\mathrm{ACHD}$

\section{Conclusions}

A four-dimensional imaging tool was useful in making the decision of re-operation in a patient with complex ACHD. We should consider comprehensively the optimal timing of surgery.

\section{Acknowledgements}

We would like to thank Editage (www.editage.jp) for English language editing.

\section{Authors' contributions}

$\mathrm{MT}, \mathrm{Kl}$, and NN managed the patient and wrote the manuscript. YK participated in the treatment of the patient and took part in writing the manuscript. KI and MY performed the operation. SM, HY, and MY supervised the whole project. The author(s) read and approved the final manuscript.

\section{Funding}

$\mathrm{Kl}$ is an endowed chair of Kyoto Prefectural University of Medicine, financially supported by Medtronic Japan

$\mathrm{KI}$ has a stock option of Cardio Flow Design Inc.

KI has patents fee from Todai Technology Licensing Organization (TLO)

$\mathrm{KI}$ is a director of Hokkaido Cardiovascular Hospital.

\section{Availability of data and materials}

Not applicable.

\section{Ethics approval and consent to participate}

Not applicable.

\section{Consent for publication}

Written informed consent was obtained from the patient for publication of this case report and any accompanying images. A copy of the written consent is available for review by the Editor-in-Chief of this journal.

\section{Competing interests}

The authors declare that they have no competing interests.

\section{Author details}

'Department of Cardiovascular Medicine, Kyoto Prefectural University of Medicine, Kyoto, Japan. ${ }^{2}$ Department of Cardiovascular Surgery, Kyoto Prefectural University of Medicine, Kyoto, Japan. ${ }^{3}$ Cardio Flow Design Inc., Tokyo, Japan. ${ }^{4}$ Department of Radiology, Kyoto Prefectural University of Medicine, Kyoto, Japan. ${ }^{5}$ Department of Pediatrics, Kyoto Prefectural University of Medicine, Kyoto, Japan. ${ }^{6}$ Department of Pediatric Cardiovascular Surgery, Kyoto Prefectural University of Medicine, Kyoto, Japan.

Received: 28 June 2019 Accepted: 28 May 2020

Published online: 23 July 2020

\section{References}

1. Kumar SR, Bansal N, Wells WJ, Starnes VA. Outcomes of reintervention on the autograft after Ross procedure. Ann Thorac Surg. 2016;102:1517-21.

2. Mokhles MM, Charitos El, Stierle U, Rajeswaran J, Blackstone EH, Bogers AJ, Takkenberg JJ, Sievers HH. The fate of pulmonary conduits after the Ross procedure: longitudinal analysis of the German-Dutch Ross registry experience. Heart. 2013;99:1857-66.

3. Zimmermann CA, Weber R, Greutmann M, Dave H, Muller C, Pretre R, Seifert $\mathrm{B}$, Buechel EV, Kretschmar O, Attenhofer Jost CH. Dilatation and dysfunction of the neo-aortic root and in 76 patients after the Ross procedure. Pediatr Cardiol. 2016:37:1175-83.

4. Zimmermann C, Attenhofer Jost C, Pretre R, Mueller C, Greutmann M, Seifert B, Valsangiacomo Buchel E, Kretschmar O, Dave HH, Weber R. Mid-term outcome of 100 consecutive Ross procedures: excellent survival, but yet to be a cure. Pediatr Cardiol. 2018:39:595-603.

5. Nelson JS, Pasquali SK, Pratt CN, Yu S, Donohue JE, Loccoh E, Ohye RG, Bove EL, Hirsch-Romano JC. Long-term survival and reintervention after the Ross procedure across the pediatric age spectrum. Ann Thorac Surg. 2015; 99:2086-94. discussion 94-95.

6. Hayashi T, Itatani K, Inuzuka R, Shimizu N, Shindo T, Hirata Y, Miyaji K. Dissipative energy loss within the left ventricle detected by vector flow mapping in children: Normal values and effects of age and heart rate. J Ccardiol. 2015;66:403-10

7. Therrien J, Provost Y, Merchant N, Williams W, Colman J, Webb G. Optimal timing for pulmonary valve replacement in adults after tetralogy of Fallot repair. Am J Cardiol. 2005;95:779-82.

8. Shibata M, Itatani K, Hayashi T, Honda T, Kitagawa A, Miyaji K, Ono M. Flow energy loss as a predictive parameter for right ventricular deterioration caused by pulmonary regurgitation after tetralogy of Fallot repair. Pediatr Cardiol. 2018;39:731-42.

9. Jang W, Kim YJ, Choi K, Lim HG, Kim WH, Lee JR. Mid-term results of bioprosthetic pulmonary valve replacement in pulmonary regurgitation after tetralogy of Fallot repair. Eur J Cardiothorac Surg. 2012;42:e1-8.

10. Greenberg NL, Vandervoort PM, Firstenberg MS, Garcia MJ, Thomas JD. Estimation of diastolic intraventricular pressure gradients by Doppler Mmode echocardiography. Am J Physiol Heart Circ Physiol. 2001;280:H250715.

11. Steine K, Stugaard M, Smiseth OA. Mechanisms of retarded apical filling in acute ischemic left ventricular failure. Circulation. 1999;99:2048-54.

12. Ohara T, Niebel CL, Stewart KC, Charonko JJ, Pu M, Vlachos PP, Little WC. Loss of adrenergic augmentation of diastolic intra-LV pressure difference in patients with diastolic dysfunction: evaluation by color M-mode echocardiography. JACC Cardiovasc Imaging. 2012;5:861-70.

13. Iwano H, Kamimura D, Fox E, Hall M, Vlachos P. Little WC. Altered spatia distribution of the diastolic left ventricular pressure difference in heart failure. J Am Soc Echocardiogr. 2015:28:597-605.e1.

14. Gopinathannair R, Sullivan R, Olshansky B. Tachycardia-mediated cardiomyopathy: recognition and management. Curr Heart Fail Rep. 2009;6: 257-64.

15. Nerheim P, Birger-Botkin S, Piracha L, Olshansky B. Heart failure and sudden death in patients with tachycardia-induced cardiomyopathy and recurrent tachycardia. Circulation. 2004;110:247-52.

16. Hunter RJ, Berriman TJ, Diab I, Kamdar R, Richmond L, Baker V, Goromonzi F, Sawhney V, Duncan E, Page SP, Ullah W, Unsworth B, Mayet J, Dhinoja M, Earley MJ, Sporton S, Schilling RJ. A randomized controlled trial of catheter ablation versus medical treatment of atrial fibrillation in heart failure (the (AMTAF trial). Circ Arrhythm Electrophysiol. 2014:7:31-8.

17. Aldaas $\mathrm{OM}$, Malladi $\mathrm{CL}, \mathrm{Hsu} \mathrm{JC}$. Catheter ablation of atrial fibrillation in patients with heart failure. Am J Cardiol. 2019:123(1):187-195.

\section{Publisher's Note}

Springer Nature remains neutral with regard to jurisdictional claims in published maps and institutional affiliations.

Ready to submit your research? Choose BMC and benefit from:

- fast, convenient online submission

- thorough peer review by experienced researchers in your field

- rapid publication on acceptance

- support for research data, including large and complex data types

- gold Open Access which fosters wider collaboration and increased citations

- maximum visibility for your research: over $100 \mathrm{M}$ website views per year

At BMC, research is always in progress.

Learn more biomedcentral.com/submissions 